\title{
Erratum to: Bias and sensitivity of proprioception of a passively felt hand path with and without a secondary task
}

Blake C. W. Martin · Kooroush Dehghan •

Denise Y. P. Henriques

Published online: 21 June 2013

(C) Springer-Verlag Berlin Heidelberg 2013

\section{Erratum to: Exp Brain Res}

DOI 10.1007/s00221-013-3572-7

In the original publication, the last name of one of the authors was inadvertently published as "Deeghan". The correct full name should read "Kooroush Dehghan".

The online version of the original article can be found under doi:10.1007/s00221-013-3572-7.

B. C. W. Martin · D. Y. P. Henriques

Centre for Vision Research, York University,

4700 Keele Street, Toronto, ON M3J1P3, Canada

B. C. W. Martin $(\varangle) \cdot$ K. Dehghan · D. Y. P. Henriques

School of Kinesiology and Health Science, York University,

4700 Keele Street, Toronto, ON M3J1P3, Canada

e-mail: blakemar@yorku.ca 